J. Amer. Soc. Hort. Sci. 121(1): 18-22. 1996.

\title{
Fused Vein Trait in Cucurbita pepo L. Associated with Subvitality of the Male Gametophyte
}

\author{
R. Bruce Carle and J. Brent Loy \\ Department of Plant Biology, University of New Hampshire, Durham, NH 03824
}

Additional index words. gametophytic selection

\begin{abstract}
Two experiments were conducted to test and delineate gametophytic subvitality of the fused vein trait in Cucurbita pepo. Gametophytic subvitality was verified by comparing pollen tube growth for fused vein and normal pollen in situ. Microscopic examination of partitioned, co-pollinated distillate flowers revealed inferior fused vein gametophyte performance. Normal pollen tubes grew faster and were significantly more abundant in the lower portion of the style. The consequences of gametophytic subvitality on seed yield and inheritance were shown by manipulating the severity of pollen competition. Fused vein, normal and $F_{1}$ lines were pollinated with fused vein, normal, $F$ and a 50:50 pollen mix at three different pollen loads. Fused vein pollen generated significantly fewer seed per fruit in all female genotypes. As a constituent in $\mathbf{F}$, or mixed pollen, it produced significant seed yield reductions at the low pollen load. In $F_{2}$ and testcross populations, a reduction in pollen load and therefore pollen competition significantly increased the number of fused vein individuals in segregating populations.
\end{abstract}

A new leaf mutant, fused vein ( $f v)$, in Cucurbita pepo has potential as a roguing marker for hull-less seeded pumpkins. The fused vein (FV) trait is expressed before flowering and imparts a distinctive, readily visible, leaf morphology (Carle and Loy, 1996a). The trait is not present among current cultivars and is likely governed by a single recessive gene (Carle and Loy, 1996b). Combined, these attributes allow early and easy outcross detection from a broad range of potential contaminants. Inheritance studies, however, suggest that the trait imparts a gametophytic subvitality that could limit its usefulness.

Gametophytes are not neutral parties in the reproductive process (Mulcahy, 1975). The numerous pollen grains deposited on a stigma are a population of haploid individuals competing to fertilize a relatively few ovules (Zamir, 1983). Selection of gametophytes changes allele frequencies in the sporophyte generation. Sporophytic traits that enhance gametophyte performance increase at the expense of those that diminish performance. Gametophytic inferiority has been associated with small plant size, reduced vigor, low fertility, and poor seed quality; all of which are important components for a seed crop (Mulcahy, 1974; Mulcahy and Mulcahy, 1975; Mulcahy et al., 1975; Ottaviano et al., 1980, 1983, 1988; Windsor et al., 1987). The FV trait does not alter plant size or vigor (Carle and Loy, 1996a). The purposes of the following studies were to confirm the FV trait's gametophytic subvitality and to determine its impact on seed production.

\section{Materials and Methods}

In situ pollen tube growth study. The FV inbred line NH2405, the normal $(\mathrm{N})$ inbred line NH614 [J.B. Loy, Univ. of New Hampshire (UNH), Durham], and their $\mathrm{F}_{1}$ hybrid were used to examine FV and N pollen tube growth. Eight plants of each line were raised in the UNH greenhouse during Spring 1992. All plants received the same cultural treatments: 9.5-liter pots, Promix soilless medium, periodic feeding with water-soluble fertilizer (Peters 20-20-20), and standard pest control.

Beginning 15 Mar. and continuing for 2 weeks, controlled co-

Received for publication 23 Jan, 1995. Accepted for publication 10 July 1995 Scientific contribution no. 1892 from the New Hampshire Agricultural Experiment Station, Durham. The cost of publishing this paper was defrayed in part by the payment of page charges. Under postal regulations, this paper therefore must be hereby marked advertisement solely to indicate this fact. pollinations were made using $\mathrm{F}_{1}$ female flowers, and $\mathrm{FV}$ and $\mathrm{N}$ male flowers. A day before anthesis, male and female flowers were identified and protected from natural pollination by tieing their corollas shut with twist ties. Following anthesis, flowers were gathered, opened, and placed in beakers of water at room temperature. Female pistils were partitioned with glass cover slips (22 $\mathrm{mm}^{2}$ ), which were inserted lengthwise through the stigma and style and into the upper $5 \mathrm{~mm}$ of each ovary. For treatment pollinations, the divided stigmas were saturated with FV pollen on one side and with $\mathrm{N}$ pollen on the other. Control pollinations consisted of both sides pollinated with either FV or $\mathrm{N}$ pollen. The female flowers were closed, retied, and left for 5 or $8 \mathrm{~h}$. Stigmas, styles, and ovaries were then removed intact, labeled, and fixed in FAA solution (90 $\mathrm{ml} 50 \%$ ethyl alcohol, $5 \mathrm{ml}$ glacial acetic acid, $5 \mathrm{ml} 40 \%$ formaldehyde) for storage and later examination. Eight treatment pollinations and two control pollinations for each pollen type were made for each time period.

The halves from each individual flower were prepared and examined concurrently. After washing thoroughly in tap water, the lower $7 \mathrm{~mm}$ of the style (style fork to ovary juncture) were removed. Pins were inserted lengthwise into the outer edge of each half to provide support. Several thin longitudinal sections were sliced from the inner surface of each half, obtaining all of the yellowish transmitting tissue of the style. Sections were placed on a glass slide, stained with aniline blue $(0.00570$ aniline blue in 0.15 $\mathrm{M} \mathrm{K}_{2} \mathrm{HPO}_{4}$ at $\mathrm{pH}$ 8.2), and gently pressed under a second glass slide. Sections were examined microscopically for the presence of pollen tubes using visible and fluorescent light. Based on cumulative counts in each section, each style half was rated for pollen tube number at both its stigma and ovary ends: 0 for no tubes, 1 for 1 20, 2 for 2140, 3 for $41-60,4$ for $61-80$, and 5 for 81 or more tubes. Pairwise $t$ test comparisons of pollen tube ratings were made for style position and pollen genotype at both time periods.

Competitive pollination study. The FV inbred line NH2405, the $\mathrm{N}$ inbred line NH614, and their $\mathrm{F}_{1}$ hybrid were used to investigate the effects of pollen competition on seed yield and FV inheritance. The lines were sown adjacent to one another in a field plot at the Woodman Horticulture Farm, Durham, N. H., on 28 May 1991. The plot consisted of 30 m rows: 4 rows for each line, 50 plants per row, $0.6 \mathrm{~m}$ between plants, and $1.8 \mathrm{~m}$ between rows. Following droughty weather and poor stand establishment, the plot was replanted on 10 June. To ensure sufficient plant material, a second plot in a nearby breeding nursery was used for one set of pollina- 
tions. The second plot was planted 30 May and consisted of $18 \mathrm{~m}$ rows, one for each line, at the same plant and row spacing as above.

From 14 July to 7 Aug., hand pollinations were made between 0700 and $1000 \mathrm{HR}$ on all three lines. Female and male flowers were identified a day before anthesis and protected from natural pollination by tieing their corollas shut with twist ties. Following anthesis, female flowers were designated at random for treatment and male flowers were collected to provide four pollen sources: $\mathrm{FV}, \mathrm{N}, \mathrm{F}_{1}$, and a 50:50 mixture (M) of FV and $\mathrm{N}$ pollens. Low, medium, and saturated pollen loads were applied to each line for each source.

The pollen loads were achieved using a method adapted from Windsor et al. (1987). For saturated pollinations, the pollen from well-dehisced anthers of two male flowers (5000+ grains) was rubbed directly onto the stigma of a single female flower. For low and medium pollinations, well-dehisced anthers from a minimum of 10 flowers were dissected into a paper cup and stirred with a glass rod to dislodge their pollen. A cotton swab cut in half was used to collect and apply pollen. A thin and uniform pollen layer on the bottom and lower $2 \mathrm{~mm}$ of the cut end formed a single application. Counts of 35 applications onto glass slides yielded on average $233(\mathrm{SD}=3.5)$ pollen grains per application. Two applications per stigma were used for the low pollen load and four applications were used for the medium load. The low level was selected to minimize pollen competition. The number of pollen grains approximated the highest seed yields obtained from pollinations in a previous inheritance study. Medium and saturated loads were chosen to respectively double and maximize competition. The 50:50 mixture treatments were accomplished by dividing applications equally between $\mathrm{FV}$ and $\mathrm{N}$ pollen.

Each day the 36 different treatment pollinations were made in groups, as complete as possible, determined by the availability of female and male flowers. Abortion of pollinated female flowers, particularly for low and medium pollen loads, resulted in incomplete and unequal numbers of fruit for pollination groups and precluded their comparison as individual replicates. By the end of the pollination period, a minimum of 15 fruit for each source at each load were set and developing on each line. Twenty openpollinated fruit were permitted to mature per line; all other developing fruit were removed to limit fruit set to two to three fruit per plant.

Growth, flowering, and fruit production were the same in both plots. Fruit were harvested in mid-September after a minimum of 40 days maturation. Each fruit was deseeded individually, and its seeds cleaned, dried, and counted. Seed counts from diseased fruit were included in analysis only if the total number of normally developed seeds could be determined. Analyses of variance for a random design with unequal subsamples were used to test for significant treatment effects. Fruit from the second plot did not constitute a complete group of treatments; plot difference was assumed to be negligible, and seed counts were combined from both plots for analysis. Mean comparisons for pollen source, pollen source within pollen load, and pollen load within pollen source were performed using least significant difference (LSD).

Pollinations that generated $\mathrm{F}_{2}$ and testcross populations were examined for FV recovery by pollen load. In three cycles of growouts from October 1991 to April 1992,30 seeds derived from each pollination $\left(F_{1} \times F_{1}: 3\right.$ low, 6 medium, 10 saturated; $F_{1} \times M$ : 5 low, 5 medium, 3 saturated; $\mathrm{FV} \times \mathrm{F}_{1}: 2$ low, 4 medium, 1 saturated; and FV $\times$ M: 3 low, 8 medium, 3 saturate) were sown in $15-\mathrm{cm}$ (1.9-liter) pots in the greenhouse. Resulting plants were grown until the tenth leaf stage and scored for leaf phenotype. Progeny were designated FV if they exhibited continual FV leaf production by the tenth leaf. All other plants were considered $N$.
Chi-square analyses were performed using one and two gene models for determining expected ratios. The frequencies of FV progeny were determined and analyzed using the Kruskal-Wallis Test and Kolmogorov-Smimov two sample comparisons (Steel and Torrie, 1980).

\section{Results}

In situ pollen tube growth. The four control blossoms showed similar pollen tube growth between their halves regardless of pollen source indicating no partition effect. Only one treatment blossom showed no tube growth whatsoever. It was judged aberrant and four missing data points were estimated following Steel and Torrie (1980). Regardless of genotype, pollen tube number increased over time and diminished with distance traveled. In two different five-hour pollinations, $\mathrm{FV}$ and $\mathrm{N}$ pollen tubes failed to reach the base of the style. In both instances, however, $\mathrm{N}$ tubes outgrew FV tubes. Pairwise $t$ test comparisons revealed that with time, there was a significant genotype effect on pollen tube growth in co-pollinated treatments (Table I). The trend of $\mathrm{N}$ pollen tubes being more abundant than FV tubes became significant at $8 \mathrm{~h}$ in the ovary end of the style (Fig. 1).

Table 1. Pairwise $t$ test comparisons of pollen tube growth by style position and by pollen genotype at 5 - and 8 -h periods.

\begin{tabular}{llc}
\hline \hline & \multicolumn{2}{c}{$t$ values } \\
\cline { 3 - 3 } Comparison & $5 \mathrm{~h}$ & $8 \mathrm{~h}$ \\
\hline Stigma vs. ovary end of style & $4.17^{* * *}$ & $5.30^{* * * *}$ \\
$\quad$ Fused vein pollen & $4.17^{* * *}$ & $0.42^{\mathrm{NS}}$ \\
$\quad$ Normal pollen & & \\
Fused vein vs. normal pollen & $1.37^{\mathrm{NS}}$ & $1.53^{\mathrm{NS}}$ \\
$\quad$ Stigma end & $1.10^{\mathrm{NS}}$ & $4.25^{* * *}$ \\
$\quad$ Ovary end &
\end{tabular}

,***Nonsignificant or significant at $P \leq 0.010$.

Effect of pollen source and load on seed yield. Pairwise LSD comparisons of open pollinated yields revealed significant differences $(P=0.05)$ among the three female genotypes (Table 2). The FV line yielded, on average, fewer seed per fruit then the $\mathrm{N}$ line, while the $F_{1}$ exhibited heterosis, out-yielding either parent. These inherent yield differences and unequal treatment replications prompted separate analyses for each female line and each cross.

Random linear models were constructed to test the effects of pollen source and pollen load on seed yield. Pollen source had a significant influence on yield for both the $\mathrm{N}(P=0.05 ; \mathrm{F}=4.29 ; \mathrm{df}$ $=3,23)$ and $\mathrm{F}_{1}$ lines $(\mathrm{P}=0.05 ; \mathrm{F}=5.14 ; \mathrm{df}=3,37)$ and was near significant for the $\mathrm{FV}$ line $(\mathrm{P}=0.10 ; \mathrm{F}=2.24$; $\mathrm{df}=3,40)$. In contrast, pollen load did not significantly alter yield when individual crosses were combined. Pollen load was, however, highly significant for two individual crosses, $\mathrm{FV} \times \mathrm{FV}(P=0.01 ; \mathrm{F}=$ 11.85; $\mathrm{df}=2,9)$ and $\mathrm{N} \times \mathrm{M}(\mathrm{P}=0.01, \mathrm{~F}=15.81, \mathrm{df}=2,7)$, and near significant for three other crosses, $\mathrm{N} \times \mathrm{F}_{1}(P=0.10 ; \mathrm{F}=3.23$; df $=$ $2,15), F_{1} \times F_{1}(P=0.10 ; F=3.24 ; d f=2,32)$, and $F_{1} \times M(P=0.10$; $\mathrm{F}=3.74 ; \mathrm{df}=2,11)$.

LSD comparison of pollen sources with combined loads, as suggested by the analysis of variance, revealed that FV pollen significantly lowered seed yield (Table 3 ). The combined load means also revealed the trend that $\mathrm{M}$ pollen produced lower average yields than $F_{1}$ pollen, which in turn produced lower yields than $\mathrm{N}$ pollen. The individual effects of pollen source by load on seed yield were also examined by pairwise LSD comparisons. FV pollen produced significantly $(P=0.05)$ lower average seed yields 


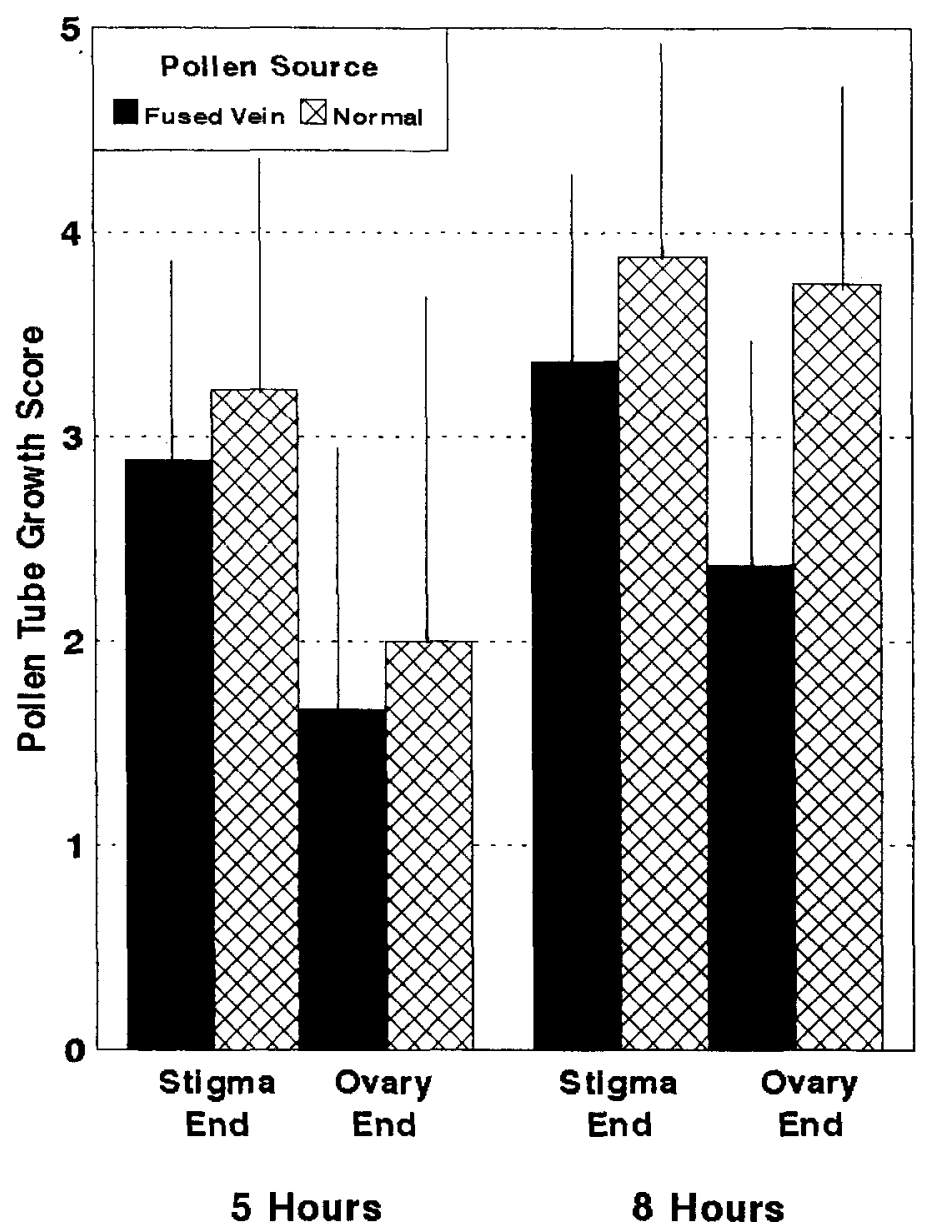

Fig. 1. Comparison of mean pollen tube growth by genotype, time, and style section. $F_{1}$ female pistils were partitioned into separate halves, one half pollinated with fused vein pollen the other pollinated with normal pollen. Pollen tube growth was scored for stigma and ovary ends of the style: 0 for no tubes, $1=1-20,2=$ $21-40,3=41-60,4=61-80$, and $5=81$ or more tubes. Thin bars represent $\mathbf{S F}$ for growth score means.

Table 2. Mean seed yield for open-pollinated fruit.

\begin{tabular}{lcccc}
\hline \hline & & \multicolumn{2}{c}{ Seed yield } & \\
\cline { 3 - 4 } Fruit type & Sample no. & Mean & Range & Standard deviation \\
\hline Fused vein & 18 & $330 \mathrm{a}^{2}$ & $121-432$ & 87.7 \\
Normal & 17 & $449 \mathrm{~b}$ & $278-638$ & 85.5 \\
$F_{1}$ hybrid & 15 & $535 \mathrm{c}$ & $264-691$ & 128.2
\end{tabular}

$\overline{{ }^{\overline{2}} \text { Different letters denote significant differences between means. Pairwise }}$ LSD tests $(\mathrm{P}<0.05)$ were used because of unequal sample numbers.

Table 3. Mean seed yield by pollen source with combined pollen loads for fused vein, normal, and $F_{1}$ fruit.

\begin{tabular}{lccc}
\hline \hline & \multicolumn{3}{c}{ Female parent } \\
\cline { 2 - 4 } Pollen source & Fused vein & Normal & $\mathrm{F}_{1}$ hybrid \\
\hline Fused vein & $169 \mathrm{a}^{2}$ & $155 \mathrm{a}$ & $273 \mathrm{a}$ \\
$50: 50$ mix & $233 \mathrm{~b}$ & $221 \mathrm{~b}$ & $356 \mathrm{~b}$ \\
F, hybrid & $240 \mathrm{~b}$ & $271 \mathrm{bc}$ & $428 \mathrm{c}$ \\
Normal & $271 \mathrm{~b}$ & $312 \mathrm{c}$ & $416 \mathrm{bc}$ \\
Open pollinated & $330 \mathrm{~b}$ & $449 \mathrm{~d}$ & $535 \mathrm{~d}$ \\
\hline
\end{tabular}

${ }^{\overline{2}}$ Different letters in the same column denote significant differences between means. Pairwise LSD tests $(P<0.05)$ were used due to the unequal number of samples for each treatment.
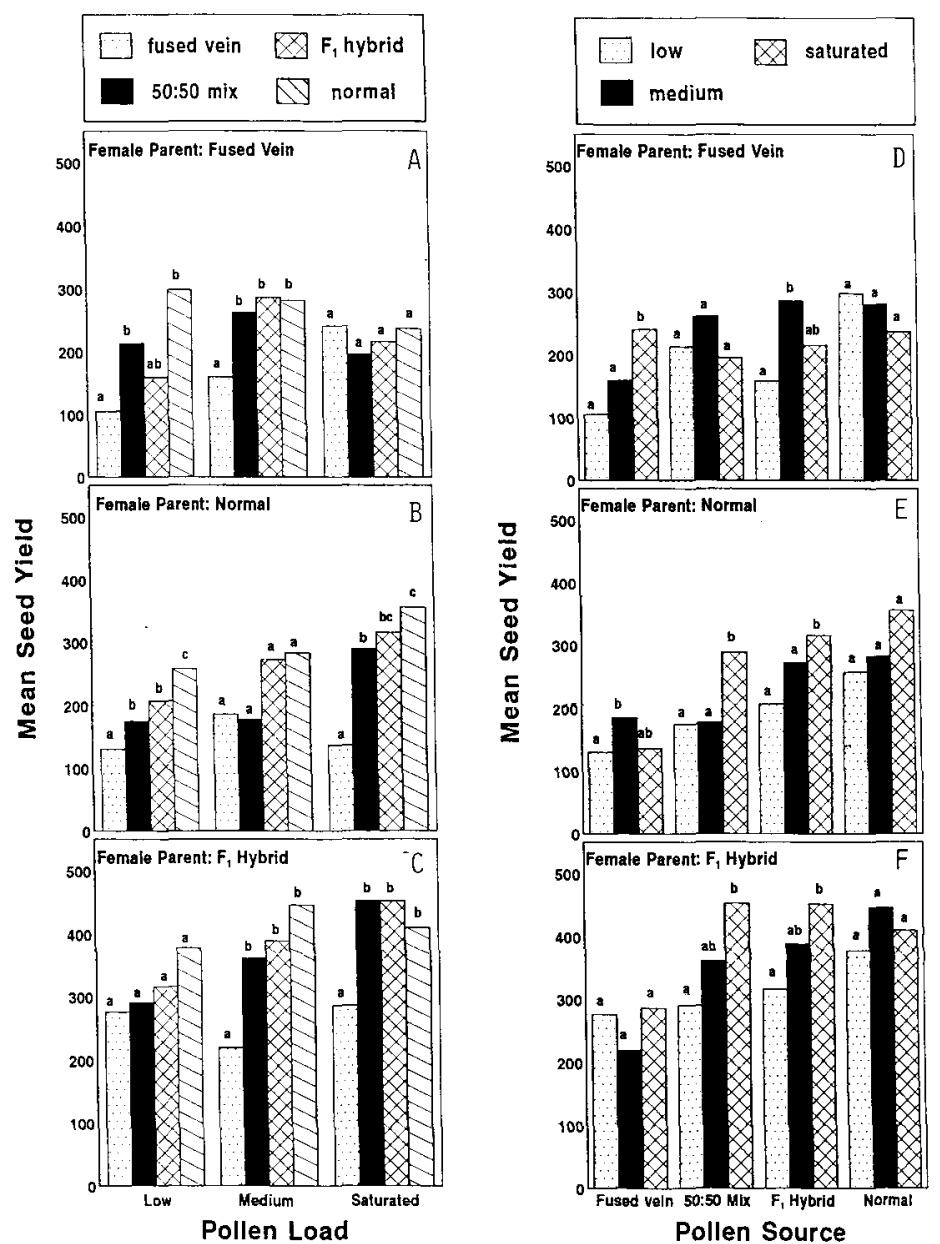

Fig. 2. Effect of pollen load (A-C) and pollen source (D-F) on average seed yield for fused vein, normal, and F, fruit. The low, medium, and saturated pollen loads were about 460,920, and 5000+ grains, respectively. Different letters within a bar cluster denote significant differences between means, Pairwise LSD tests $(P<$ $0.05)$ were used due to the unequal number of samples for each treatment.

than $\mathrm{N}$ pollen for six of the nine sets of load by source comparisons (Fig. 2 A-C) In general, N, $\mathrm{F}_{1}$, and $\mathrm{M}$ pollen were not significantly different from each other. $\mathrm{N}$ pollen, however, produced the highest average yields, particularly at the low pollen load. Although the analyses of variance indicated no significant pollen load effect, LSD comparisons showed decreased seed yields at the low pollen load, relative to the saturated load, for a majority of crosses involving $\mathrm{FV}, \mathrm{F}_{1}$, and $\mathrm{M}$ pollen (Fig. $2 \mathrm{D}-\mathrm{F}$ ). In contrast, crosses with $\mathrm{N}$ pollen showed no significant decreases, suggesting a weakness of the FV gametophyte.

Pollen competition and FV recovery. The frequencies of FV progeny obtained in $\mathrm{F}_{2}$ and testcross populations varied considerably. As in previous inheritance studies (Carle and Loy, 1996b), chi square analysis showed fit to both single and double recessive gene models for both $\mathrm{F}_{2}$ (Fig. 3) and testcross populations (Fig. 4). However, fit was also associated with pollen load. Only one single gene fit occurred at the saturated pollen loads. Single gene fit predominated at the low load for testcross populations and at the medium load for $F_{2}$ populations. Failure to recover FV individuals occurred only at the saturated load for $F_{2}$ populations generated with $F_{1}$ pollen.

Because the distribution of $\mathrm{F}_{2} \mathrm{FV}$ frequencies obtained with saturated $F_{1}$ pollen was skewed, data were analyzed nonparametrically. Kruskal-Wallis analysis revealed a significant pollen load effect, but no significant difference between pollen sources for both the $\mathrm{F}_{2}$ and 


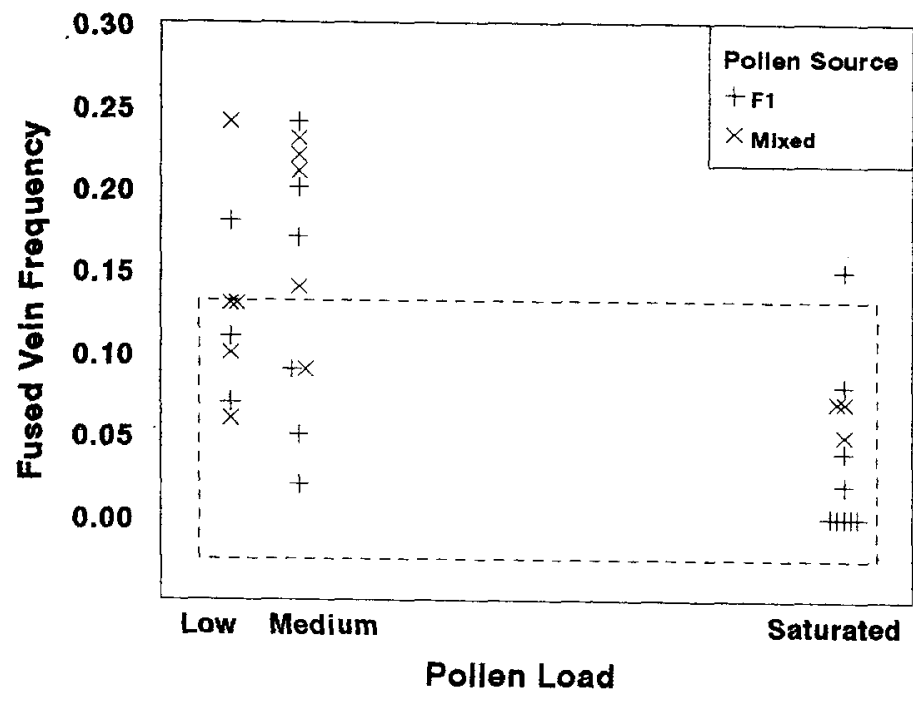

Fig. 3. Fused vein recovery by pollen load for $\mathrm{F}_{2}$ populations derived from (NH2405 $\times$ NH614) pollinated with $\mathrm{F}_{1}$ or a 50:50 mixture of fused vein and normal pollen. The low, medium, and saturated pollen loads were about 460, 920, and 5000+ grains, respectively. Populations outside of the dashed box fit a single gene model, while those within fit a double recessive model as determined by chi square analyses, critical $\boldsymbol{P}$ value of 0.05 .

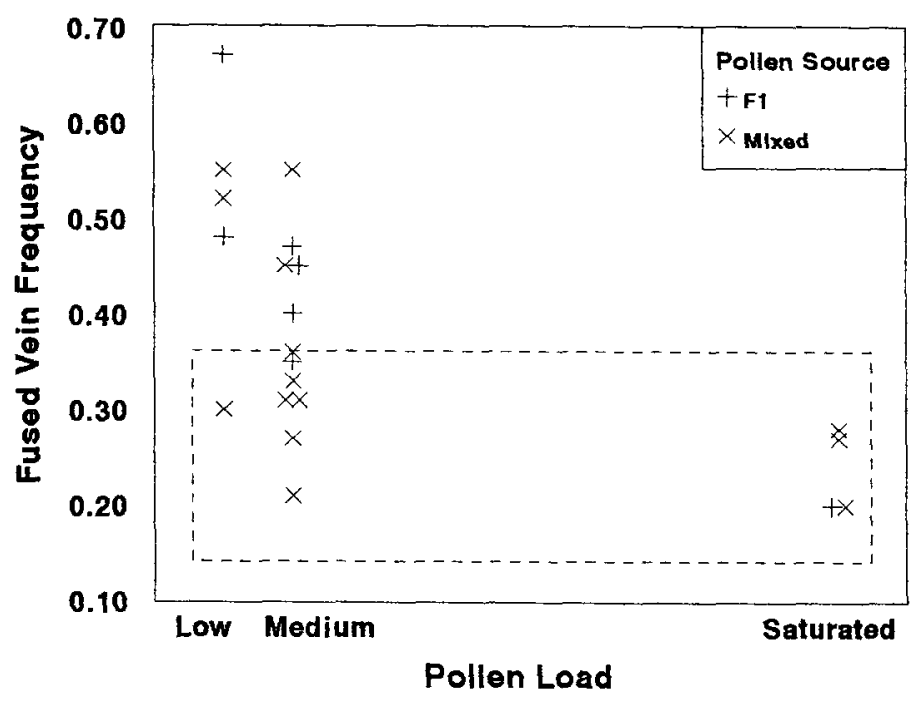

Fig. 4. Fused vein recovery for testcross populations derived from NH2405 pollinated with $\mathrm{F}_{1}$ or a 50:50 mixture of fused vein and normal pollen. The low, medium, and saturated pollen loads were about 460, 920, and 5000+ grains, respectively. Populations outside of the dashed box fit a single gene model, while those within fit a double recessive model as determined by chi-square analyses, critical $\mathrm{P}$ value of 0.05 .

testcross populations. Kolmogorov-Smimov two sample comparisons, with separate or combined pollen sources for both population groups, showed significantly lower FV frequencies for the saturated pollen load when compared to the low and medium loads (Table 4). The low and medium loads were only significantly different from each other in the testcross populations.

\section{Discussion}

In previous inheritance studies, Carle and Loy (1996b) hypothesized that the FV trait is governed by a single recessive gene, whose low and erratic inheritance results from gametophytic subvitality. The concept of gametophytic selection maintains that the male gametophyte genome imparts a functional ability, which
Table 4. Mean fused vein frequencies for $\mathrm{F}_{2}$ and backcross populations by pollen load and pollen source.

\begin{tabular}{|c|c|c|c|c|c|}
\hline \multirow{2}{*}{$\begin{array}{l}\text { Pollen } \\
\text { load }\end{array}$} & \multicolumn{2}{|r|}{$\mathrm{F}_{2}$} & \multicolumn{3}{|c|}{ Backcross } \\
\hline & $F_{1}$ & Mixed Combined & $\mathrm{F}_{1}$ & Mixed & Combined \\
\hline Low & $0.118 \mathrm{a}^{z}$ & $0.132 \mathrm{ab} \quad 0.128 \mathrm{a}$ & $0.576 \mathrm{a}$ & $0.456 \mathrm{a}$ & $0.503 \mathrm{a}$ \\
\hline Medium & $0.127 \mathrm{a}$ & $0.178 \mathrm{a} \quad 0.151 \mathrm{a}$ & $0.415 \mathrm{~b}$ & $0.349 \mathrm{ab}$ & $0.372 \mathrm{~b}$ \\
\hline
\end{tabular}

${ }^{2}$ Different letters in the same column denote significantly different means, Kolmogorov-Smirnov ranked two sample tests $(P<0.05)$.

is tested by the competitive processes of plant reproduction, resulting in the preferential transmission of superior alleles (Mulcahy, 1975; Zamir, 1983). Accordingly, any sporophytic trait, whose alleles differentially affect gametophytic function, will exhibit distorted patterns of Mendelian inheritance and will be influenced by factors affecting reproductive competition.

Both the pollen tube growth and pollen competition studies demonstrated the subvitality of the FV male gametophyte. FV pollen tubes grew more slowly and were relatively less abundant in the style than $\mathrm{N}$ pollen tubes. FV pollen generated significantly fewer seeds per fruit than $\mathrm{N}$-pollen in all female genotypes. Its fecundity, unlike $\mathrm{N}$ pollen, decreased with pollen load. Seed yields for FV, F, and $\mathrm{M}$ pollinations decreased with load while $\mathrm{N}$ yields remained stable. Relaxing reproductive competition also characteristically increased the recovery of FV segregants. These results indicate that the FV male gametophyte is less successful at traversing the reproductive path, achieving fertilization, and realizing normal seed development.

Presumably, the variability of FV inheritance and seed yields results not only from a difference in base level gametophytic ability but from differential sensitivities to changing environmental conditions. The effects of the environment on the reproductive success of $C$. pepo and other cucurbits is well documented; it influences flower production and anthesis (Seaton and Kremer, 1938; Sedgley and Buttrose, 1978), pollen quality and transmission (Hutton, 1988; Iapichino and Loy, 1987; Maestro and Alvarez, 1988; Matlop and Kelly, 1973; Sedgley and Buttrose, 1978), and set of fruit and seed (Bushnell, 1920; Mann and Robinson, 1950; Porter, 1933). In particular, Gay and colleagues (1987) have shown that $C$. pepo pollen germination and tube growth is sensitive to ageing and dehydration. Differential gametophyte performance to temperature stress has also been shown for Cucumis melo (Hutton, 1988; Maestro and Alvarez, 1988). We assume that the difference between $\mathrm{FV}$ and $\mathrm{N}$ gametophyte performance only widens with adverse conditions.

The gametophytic subvitality of the FV trait narrows its effectiveness as a roguing marker for hull-less seeded pumpkins. Successful hull-less seeded cultivars must not only be free of offtypes, but must have acceptable plant and fruit characteristics and, importantly, a high seed yield. Although the FV trait does not adversely alter plant growth or structure (Carle and Loy, 1996a), theoretically its inferior gametophytic fertility should reduce the potential seed yield of a FV cultivar relative to an isogenic $\mathrm{N}$ cultivar. Nonetheless, the predominance of hybrid cultivars provides a solution. A FV by $\mathrm{N}$ hull-less seeded hybrid permits partial exploitation of the trait's morphological uniqueness while avoiding its adverse effect on yield. The distinctive juvenile morphology of the FV trait facilitates increase and maintenance of the female parent. Hulled, normal offtypes are easily identified and removed from parent and hybrid production fields before contamination can spread. Although increase of the $\mathrm{N}$ male parent requires more stringent and costly control, the smaller quantity of seed of the 
male parent required for hybrid production reduces the frequency of male inbred increases and spreads the added cost over several hybrid productions. As a heterozygote, the hybrid has a $\mathrm{N}$ leaf phenotype and produces ample $\mathrm{N}$ pollen to compensate for the reduced fertility of its $\mathrm{FV}$ pollen. As an added advantage, its $\mathrm{N}$ phenotype enables easy detection of FV inbred contamination in hybrid seed lots.

\section{Literature Cited}

Bushnell, J.W. 1920. The fertility and fruiting habit of the cucurbita. Proc. Amer. Soc. Hort. Sci. 17:47-51.

Carle, R.B. and J.B. Loy. 1996a. Morphology and anatomy of the fused vein trait in Cucurbita pepo L. J. Amer. Soc. Hort. Sci. 121:6-12.

Carle, R.B. and J.B. Loy. 1996b. Genetic analysis of the fused vein trait in Cucurbita pepo L. J. Amer. Soc. Hort. Sci. 121:13-17.

Gay, G., C. Kerhoas and C. Dumas. 1987. Quality of stress-sensitive Cucurbita pepo L. pollen. Planta 171:82-87.

Hutton, M.G. 1988. Genetics and physiology of cold tolerance in muskmelon Cucumis melo L. PhD diss., Univ. of New Hampshire

Iapichino, G.F. and J.B. Loy. 1987. High temperature stress affects pollen viability in bottle gourd. J. Amer. Soc. Hort. Sci. 112:372-374.

Maestro, C.A. and J. Alvarez. 1988. The effects of temperature on pollination and pollen tube growth in muskmelon (Cucumis melo L.). Scientia Hort. 36:173-181.

Mann, L.K. and Robinson, J. 1950. Fertilization, seed development, and fruit growth as related to fruit set in the cantaloupe (Cucumis melo L.). Amer. J. Bet. 37:685-697.

Matlop, A.N. and W.C. Kelly. 1973. The effect of high temperature on pollen tube growth of snake-melon and cucumber. J. Amer. Soc. Hort. Sci. 98:296-300.

Mulcahy, D.L. 1974. Correlation between speed of pollen tube growth and seedling height in Zea mays L. Nature 249:491493.

Mulcahy, D.L. 1975. The biological significance of gamete competition, p. 1-3. In: D.L. Mulcahy (ed.). Gamete competition in plants and animals. North Holland Publ. Co., Amsterdam.

Mulcahy, D.L. and G.B. Mulcahy. 1975. The influence of gametophytic competition on sporophytic quality in Dianthus chinensis. Theoret. Appl. Genet. 46:277-280.

Mulcahy, D. L., G.B. Mulcahy, and E. Ottaviano. 1975. Sporophytic expression of gametophytic competition in Petunia hybrids, p. 227 232. In: D.L. Mulcahy (ed.). Gamete competition in plants and animals. North Holland Publishing Co., Amsterdam.

Ottaviano, E., D. Petroni, and M.E. Pe'. 1988. Gametophytic expression of genes controlling endosperm development in maize. Theoret. Appl. Genet. 75:252-258.

Ottaviano, E., M. Sari-Gorla, and 1. Arenare. 1983. Male gametophytic competitive ability in maize selection and implications with regard to breeding systems, p. 367-374. In: D.L. Mulcahy and E. Ottaviano (eds.). Pollen-Biology and implications for plant breeding. Elsevier, New York.

Ottaviano; E., M. Sari-Gorla, and D.L. Mulcahy. 1980. Pollen tube growth rates in Zea mays - Implications for genetic improvement of crops. Science 210:437438.

Porter, D.R. 1933. Watermelon breeding. Hilgardia 7:585-624.

Seaton, H.L. and J.C. Kremer. 1938. The influence of climatological factors on anthesis and anther dehiscence in the cultivated cucurbits. Proc. Amer. Soc. Hort. Sci. 36:627-631.

Sedgley, M. and M.S. Buttrose. 1978. Some effects of light intensity, daylength, and temperature on flowering and pollen tube growth in the watermelon (Citrullus lanatus). Ann. Bot. 42:609-616.

Steel, R.G.D. and J.H. Torrie. 1980. Principles and procedures of statistics-A biometrical approach. 2nd ed. McGraw Hill, New York.

Windsor, J.A, L.E. Davis, and A.G. Stephenson. 1987. The relationship between pollen load and fruit maturation and the effect on pollen load on offspring vigor in Cucurbita pepo. Amer. Nat. 129:643-656.

Zamir, D. 1983. Pollen gene expression and selection: applications to plant breeding, p. 3 13-330. In: S.D. Tanksley and T.J. Orton (eds.). Isozymes in plant genetics and breeding, part A. Elsevier, New York. 